\title{
A Comparison of ITM and OTM Protective-Puts and Covered-Calls
}

\author{
Mihir Dash \\ Department of Quantitative Methods, School of Business, Alliance University \\ Chikkahagade Cross, Chandapura-Anekal Road, Anekal, Bangalore \\ E-mail: mihirda@rediffmail.com \\ Ankush Goel \\ Research Scholar, School of Business, Alliance University \\ Chikkahagade Cross, Chandapura-Anekal Road, Anekal, Bangalore
}

Received: June 30, 2013 Accepted: March 4, 2014 Published: June 1, 2014

doi:10.5296/ajfa.v6i1.3945 URL: http://dx.doi.org/10.5296/ajfa.v6i1.3945

\begin{abstract}
The diverse uses of derivatives arise from the skewing effect that options strategies have on the returns distribution of portfolios. In particular, it is widely believed that the performance of pure-stock portfolios can be enhanced by incorporating different options strategies, the most popular strategies being protective-put buying and covered-call writing.

The present study considers these two popular options strategies, and applies them to a sample of fifty-five stocks listed in National Stock Exchange F\&O segment, using corresponding stock options, in order to find out which of these strategies yields maximum returns, as compared to a pure-stock position. The study also compares the performance of in-the-money (ITM) and out-of-the-money (OTM) protective-put buying and covered-call writing.

The results of the study suggest that protective-put buying performs better overall than covered-call writing, and that the mean and standard deviation of the returns distribution of the underlying stock affected the optimal strategy: buying protective-puts was optimal for stocks for which the returns distribution had relatively higher mean values and lower standard deviations, while selling covered-calls was optimal for stocks for which the returns distribution had relatively lower mean values and higher standard deviations.
\end{abstract}

Keywords: Derivatives, Options strategy, Covered-call writing, Protective put buying, In-the-money (ITM), Out-of-the money (OTM) 


\section{Introduction}

Derivatives, which were originally introduced as financial instruments to hedge financial risk, are now increasingly used for speculative purposes as well. The diverse uses of derivatives arise from the skewing effect that options strategies have on the returns distribution of portfolios. In particular, it is widely believed that the performance of pure-stock portfolios can be enhanced by incorporating different options strategies, the most popular strategies being covered-call writing and protective-put buying. Theoretically and empirically, however, there is no clear evidence on whether this is really the case. The general framework suggested by Hakanson (1978), Cox (1976) and Ross (1976) indicates that incorporating option strategies enhances the general efficiency of financial markets by increasing the number of investment opportunities available to investors in terms of insurance and hedging. On the other hand, options can themselves be used as short-term investment instruments, and can improve portfolio performance when used speculatively (Dash et al, 2007).

The present study investigates the effect of option buying and writing strategies on the returns of an (unhedged) stock position. The objective of the study was to find out the optimal strategies (i.e. that yield maximum returns), to compare the returns of covered-call and protective-put strategies, and to compare the returns of ITM and OTM options combinations.

\section{Literature Review}

Several studies compare the performance of pure-stock positions with that of stock positions combined with options, and the performance of different option strategies. Trennepohl and Dukes (1981) investigated the performance of option writing and buying strategies using in-the-money (ITM) and out-of-the-money (OTM) options, and found that covered option writing lowers portfolio standard deviation and improves portfolio mean returns. Bookstaber and Clarke (1984) compared the performance of protective-put, covered-call, and pure-stock strategies, and found that call writing is better than put buying in terms of expected return and volatility, but that the former truncates the right-hand side of a distribution causing undesirable negative skewness, while put-buying truncates the left-hand side of a distribution causing desirable positive skewness. Castellano and Giacometti (2001) compared the performance of protective-put and covered-call strategies to the performance of holding an unhedged currency portfolio and found that the option strategies perform better than the optimal naked portfolios and the protective-put strategy performs well for different VaR models. Isakov and Morard (2001) investigated the performance of a global investment strategy that combines diversification and option strategies, in particular the covered call strategy, and found that the use of option strategies consistently improves the performance of stock portfolios, even in the presence of transaction costs. Abid et al (2009) investigated the performance of option strategies, including writing OTM covered-call and buying ITM protective put, with that of the pure-stock investment, and found that, in general, the buying ITM protective-put strategy has the best performance, followed by the writing OTM covered-call strategy, both out-performing the naked stock.

Some studies show that the performance of option strategies with stock portfolios could depend on other factors or on market conditions. Benninga and Blume (1985) analyzed the 
optimality of portfolio insurance in complete and incomplete markets, and found that buying put option may be optimal only in an incomplete market, not in a complete market. Brooks and Hand (1988) examined the return characteristics of index futures contracts, and found that both the return distribution and performance evaluation depend on the risk-free rate, the dividend rate, the basis and the margins.

The current study follows the approach of Dash et al (2008), who have also analysed the effect of options strategies on a pure-stock position. They identified two types of optimal options strategies: one which yielded highest returns at the lowest strike price ( $5 \%$ below the initial stock price) and for which the returns decreased with increase in strike price; and one which yielded highest returns at the highest strike price ( $5 \%$ above the initial stock price) and for which the returns decreased with decrease in strike price, termed as "optimal in the first sense" and "optimal in the second sense," respectively. The results of their study show that two were two strategies that were optimal more than $60 \%$ of the time: "hold stock, buy call" (in the first sense), and "hold stock, sell put" (in the second sense); and that these two strategies were very strongly associated with each other. In fact, the covered-call and protective-put strategies, which were so widely investigated in the literature, were optimal only to a marginal extent ( $0.8 \%$ of the time). Further, the optimal strategies were found to be discriminated by the standard deviation, the skewness, and the kurtosis of the daily returns of the underlying stock; and the returns of the optimal strategies were found to be related to the kurtosis of the daily returns of the underlying stock. In particular, skewness and kurtosis in the daily returns of the underlying stock tended to favour to more aggressive options positions, suggesting that the optimal strategies were influenced by abnormal tail behaviour of the daily returns of the underlying stock.

Overall from the literature it can be concluded that option introduction improves the performance of portfolios significantly, but there are mixed results concerning whether covered-calls or protective-puts perform better. The present study addresses this question explicitly.

\section{Data \& Methodology}

The present study was undertaken to analyse the effect of options strategies on a pure-stock position. To this end, two stock-option combinations were considered: buying protective-puts (i.e. holding the stock, and buying a put-option on the same stock) and selling covered-calls (i.e. holding the stock, and writing a call-option on the same stock). The sample stocks used for the study were those stock listed on the National Stock Exchange (NSE), Mumbai, India, for which the corresponding derivatives were actively traded on the National Stock Exchange Futures \& Options segment, thus constituting a judgmental sample. The sample size was fifty-five such stocks. The time period considered for the study was $1^{\text {st }}$ October 2007 to $27^{\text {th }}$ December 2007.

The option-stock combinations considered for the study were static strategies: it was assumed that, for a particular option-stock combination, the position was entered on the first day of the study period and maintained until expiration on the last day of the study period. The data used for the study consisted of the opening prices of the stocks and option premia of the stock 
options at different strike prices on the first day of the study period and the closing prices of the stocks on the last day of the study period obtained from the NSE archives.

For each stock option, five strike prices were available initially: at par with the initial stock price, $2 \%$ below the initial stock price, $5 \%$ below the initial stock price, $2 \%$ above the initial stock price, and 5\% above the initial stock price. In this context, for each stock, the option strategies were classified as either in-the-money (ITM) or out-of-the-money (OTM) strategies, at the time of entering into the contract. For each stock-option combination, returns were computed as the excess of the payoff from the stock-option combination over the payoff from the pure-stock position, in proportional terms.

\section{Analysis \& Interpretation}

It was found that for $94.55 \%$ of the sample stocks, the stock-option combinations overall yielded higher returns as compared to a pure-stock position. In particular, buying ITM protective-puts yielded higher returns as compared to a pure-stock position for $56.36 \%$ of the sample stocks; buying OTM protective-puts yielded higher returns as compared to a pure-stock position for $58.18 \%$ of the sample stocks; selling OTM covered-calls yielded higher returns as compared to a pure-stock position for $36.36 \%$ of the sample stocks; and selling ITM covered-calls yielded higher returns as compared to a pure-stock position for $34.55 \%$ of the sample stocks. Overall, it was found that buying ITM protective-puts were optimal for $32.73 \%$ of the sample stocks; buying OTM protective-puts were optimal for $25.45 \%$ of the sample stocks; selling OTM covered-calls were optimal for $29.09 \%$ of the sample stocks; and selling ITM covered-calls were optimal for $12.73 \%$ of the sample stocks. Thus, buying protective-puts was optimal for $58.18 \%$ of the sample stocks, while selling covered-calls was optimal for $41.82 \%$ of the sample stocks.

Comparing the returns from the different options combinations, it was found that selling ITM covered-calls yielded better returns than selling OTM covered-calls for $45.45 \%$ of the sample stocks, and vice versa for $54.55 \%$ of the sample stocks; selling ITM covered-calls yielded better returns than buying ITM protective-puts for 38.18\% of the sample stocks, and vice versa for $61.82 \%$ of the sample stocks; selling ITM covered-calls yielded better returns than buying OTM protective-puts for $40.00 \%$ of the sample stocks, and vice versa for $60.00 \%$ of the sample stocks; selling OTM covered-calls yielded better returns than buying ITM protective-puts for $43.64 \%$ of the sample stocks, and vice versa for $56.36 \%$ of the sample stocks; selling OTM covered-calls yielded better returns than buying OTM protective-puts for $43.64 \%$ of the sample stocks, and vice versa for $56.36 \%$ of the sample stocks; and buying ITM protective-puts yielded better returns than initial buying OTM protective-puts for $54.55 \%$ of the sample stocks, and vice versa for $45.45 \%$ of the sample stocks. In fact, two specific patterns were observed very frequently: for $29.09 \%$ of the sample stocks, buying ITM protective-puts yielded higher mean returns than buying OTM protective-puts, which in turn yielded higher mean returns than selling ITM covered-calls, which further yielded higher mean returns than selling OTM covered-calls, and for $23.64 \%$ of the sample stocks, buying OTM protective-puts yielded higher mean returns than buying ITM protective-puts, which in 
turn yielded higher mean returns than selling OTM covered-calls, which further yielded higher mean returns than selling ITM covered-calls.

The comparison of returns of the different stock-option combinations is presented in Table 1 .

Table 1. Correlation and t-tests for differences in returns of different stock-option strategies

\begin{tabular}{|c|c|c|c|c|c|c|c|}
\hline & strategy pairs & mean & std. dev. & $\begin{array}{l}\text { paired-samples } \\
\text { correlation }\end{array}$ & p-value & $\begin{array}{l}\text { paired-samples } \\
\text { t-test for means }\end{array}$ & p-value \\
\hline \multirow{2}{*}{$\begin{array}{l}\text { pair } \\
1\end{array}$} & sell ITM covered-call & -1.2955 & 2.3326 & 0.8583 & 0.0000 & 0.2479 & 0.8052 \\
\hline & sell OTM covered-call & -1.3400 & 2.5823 & & & & \\
\hline \multirow{2}{*}{$\begin{array}{l}\text { pair } \\
2\end{array}$} & sell ITM covered-call & -1.2955 & 2.3326 & -0.4888 & 0.0002 & -3.6247 & $0.0006^{* *}$ \\
\hline & buy ITM protective-put & 0.9482 & 2.9749 & & & & \\
\hline \multirow{2}{*}{$\begin{array}{l}\text { pair } \\
3\end{array}$} & sell ITM covered-call & -1.2955 & 2.3326 & -0.4366 & 0.0009 & -3.2633 & $0.0019 * *$ \\
\hline & buy OTM protective-put & 0.5840 & 2.7019 & & & & \\
\hline \multirow{2}{*}{$\begin{array}{l}\text { pair } \\
4\end{array}$} & sell OTM covered-call & -1.3400 & 2.5823 & -0.7148 & 0.0000 & -3.2965 & $0.0017^{* *}$ \\
\hline & buy ITM protective-put & 0.9482 & 2.9749 & & & & \\
\hline \multirow{2}{*}{$\begin{array}{l}\text { pair } \\
5\end{array}$} & sell OTM covered-call & -1.3400 & 2.5823 & -0.5656 & 0.0000 & -3.0517 & $0.0035^{* *}$ \\
\hline & buy OTM protective-put & 0.5840 & 2.7019 & & & & \\
\hline \multirow{2}{*}{$\begin{array}{l}\text { pair } \\
6\end{array}$} & buy ITM protective-put & 0.9482 & 2.9749 & 0.9509 & 0.0000 & 2.9068 & $0.0053^{* *}$ \\
\hline & buy OTM protective-put & 0.5840 & 2.7019 & & & & \\
\hline
\end{tabular}

It was found that the returns from the protective-put combinations were negatively correlated to the returns from the covered-call combinations. Further, overall, buying ITM protective-puts yielded the highest mean returns, followed by buying OTM protective-puts, selling ITM covered-calls, and finally, selling OTM covered-calls. In fact, the mean returns from ITM protective-puts were significantly higher than those of other strategies, and the mean returns from buying protective puts were significantly higher than the mean returns from selling covered-calls. Also, the mean returns from buying ITM protective-puts were found to be significantly higher than the mean returns from buying OTM protective-puts; while there was no significant difference in the mean returns from selling ITM and OTM covered-calls.

In order to further investigate the different optimal strategies, the relationships between the optimal strategies and the characteristics of the returns distribution of the underlying stock were analysed. The characteristics of the returns distribution of the underlying stock for different optimal strategies are shown in Table 2 and Table 3. 
Table 2. Characteristics of the returns distribution of underlying stocks for different stock-option strategies

\begin{tabular}{|l|c|c|c|c|c|c|c|}
\hline & $\begin{array}{c}\text { buy ITM } \\
\text { protective-put }\end{array}$ & $\begin{array}{c}\text { buy OTM } \\
\text { protective-put }\end{array}$ & $\begin{array}{c}\text { sell ITM } \\
\text { covered-call }\end{array}$ & $\begin{array}{c}\text { sell OTM } \\
\text { covered-call }\end{array}$ & overall & F-test & p-value \\
\hline mean stock returns & $0.6224 \%$ & $0.2118 \%$ & $0.3940 \%$ & $0.4287 \%$ & $0.4325 \%$ & 1.6087 & $0.0994 *$ \\
\hline stdev stock returns & $4.0133 \%$ & $3.0578 \%$ & $3.4651 \%$ & $3.1631 \%$ & $3.4530 \%$ & 1.8584 & $0.0742 *$ \\
\hline skewness stock returns & 0.6256 & 0.2603 & -0.2041 & 0.4101 & 0.3643 & 0.8871 & 0.2272 \\
\hline kurtosis stock returns & 2.5243 & 4.4215 & 3.5436 & 1.3707 & 2.8014 & 0.6860 & 0.2824 \\
\hline
\end{tabular}

Table 3. Characteristics of the returns distribution of underlying stocks for buying protective puts vs. selling covered-calls

\begin{tabular}{|l|c|c|c|c|c|}
\hline & buy protective-puts & sell covered-calls & overall & F-test & p-value. \\
\hline mean stock returns & $0.4428 \%$ & $0.4181 \%$ & $0.4325 \%$ & 0.0278 & 0.4341 \\
\hline stdev stock returns & $3.5953 \%$ & $3.2550 \%$ & $3.4530 \%$ & 0.8960 & 0.1741 \\
\hline skewness stock returns & 0.4658 & 0.2231 & 0.3643 & 0.5693 & 0.2269 \\
\hline kurtosis stock returns & 3.3544 & 2.0320 & 2.8014 & 0.6516 & 0.2116 \\
\hline
\end{tabular}

There were found to be significant differences in the mean stock returns and standard deviation of stock returns for different optimal strategies, but no significant difference in the skewness and kurtosis of stock returns for different optimal strategies. The optimal strategy of buying ITM protective-puts was found to be associated with high mean returns, high standard deviation of returns, moderate positive skewness, and slight platy-kurtosis; the optimal strategy of buying OTM protective-puts was found to be associated with low mean returns, moderate standard deviation of returns, slight positive skewness, and slight lepto-kurtosis; the optimal strategy of selling ITM covered-calls was found to be associated with moderate mean returns, moderate standard deviation of returns, moderate negative skewness, and slight lepto-kurtosis; and the optimal strategy of selling OTM covered-calls was found to be associated with moderate mean returns, moderate standard deviation of returns, moderate positive skewness, and moderate platy-kurtosis. There were found to be no significant difference in the mean stock returns, standard deviation of stock returns, skewness of stock returns, and kurtosis of stock returns between optimal buying protective-puts and optimal selling covered-calls; optimal buying protective-puts was found to be associated with higher skewness and kurtosis than optimal selling covered-calls.

The results of regression analysis of optimal returns on the characteristics of the distribution of the underlying stock are shown in Table 4. 
Table 4. Regression of optimal returns on the characteristics of the distribution of underlying stocks

\begin{tabular}{|l|c|c|c|c|}
\hline & $\begin{array}{c}\text { Unstandardized } \\
\text { Coefficients }\end{array}$ & $\begin{array}{c}\text { Standardized } \\
\text { Coefficients }\end{array}$ & t-test & p-value \\
\hline mean stock returns & -232.9297 & -0.5212 & -2.4160 & $0.0193^{*}$ \\
\hline stdev stock returns & 80.7126 & 0.9729 & 4.0223 & $0.0002 * *$ \\
\hline skewness stock returns & 0.0971 & 0.0386 & 0.2776 & 0.7824 \\
\hline kurtosis stock returns & 0.0157 & 0.0335 & 0.2178 & 0.8284 \\
\hline
\end{tabular}

The standard deviation of returns and the mean returns of the underlying stock were found to have significant impact on the optimal returns, while the skewness and kurtosis of returns of the underlying stock were not found to have a significant impact on the optimal returns. Moreover, the optimal returns were found to be positively correlated with the standard deviation of returns of the underlying stock, other characteristics remaining constant, and negatively correlated with the mean returns of the underlying stock, other characteristics remaining constant. Together, the characteristics of the returns distribution of the underlying stock explained $42.1 \%$ of the variation in optimal returns.

The results of regression analysis of the optimal strategy on the characteristics of the distribution of the underlying stock are shown in Table 5.

Table 5. Regression of optimal strategy on the characteristics of the distribution of underlying stocks

\begin{tabular}{|l|c|c|c|c|}
\hline & $\begin{array}{c}\text { Unstandardized } \\
\text { Coefficients }\end{array}$ & $\begin{array}{c}\text { Standardized } \\
\text { Coefficients }\end{array}$ & t-test & p-value \\
\hline mean stock returns & -30.6465 & -0.3246 & -1.4593 & 0.1506 \\
\hline stdev stock returns & 18.1371 & 1.0350 & 4.1495 & $0.0001^{* *}$ \\
\hline skewness stock returns & -0.0839 & -0.1578 & -1.1010 & 0.2761 \\
\hline kurtosis stock returns & -0.0291 & -0.2949 & -1.8589 & $0.0688^{*}$ \\
\hline
\end{tabular}

The standard deviation of returns, the mean returns, and the kurtosis of returns of the underlying stock were found to have significant impact on the optimal returns, while the skewness of returns of the underlying stock was not found to have a significant impact on the optimal strategy. Moreover, the optimal strategy was more likely to involve buying protective-puts for lower standard deviation of returns of the underlying stock and selling covered-calls for higher standard deviation of returns, other characteristics remaining constant; and vice versa for the other characteristics. Together, the characteristics of the returns distribution of the underlying stock explained $38.4 \%$ of the variation in optimal strategy. 


\section{Macrothink}

Asian Journal of Finance \& Accounting

ISSN 1946-052X 2014, Vol. 6, No. 1

The results of regression analysis of the optimal strategy on the dominance relations between different strategies are shown in Table 6.

Table 6. Regression of optimal strategy on the dominance relations between different strategies

\begin{tabular}{|l|c|c|c|c|}
\hline & $\begin{array}{c}\text { Unstandardized } \\
\text { Coefficients }\end{array}$ & $\begin{array}{c}\text { Standardized } \\
\text { Coefficients }\end{array}$ & t-test & p-value \\
\hline $\begin{array}{l}\text { OTM covered-call dominates } \\
\text { OTM protective-put }\end{array}$ & 0.4000 & 0.4086 & 5.8878 & $0.0000^{* *}$ \\
\hline $\begin{array}{l}\text { OTM covered-call dominates } \\
\text { ITM protective-put }\end{array}$ & 0.4000 & 0.4086 & 5.8878 & $0.0000^{* *}$ \\
\hline $\begin{array}{l}\text { ITM covered-call dominates } \\
\text { ITM protective-put }\end{array}$ & 0.2000 & 0.1911 & 3.4084 & $0.0013^{* *}$ \\
\hline
\end{tabular}

The optimal strategy was found to be significantly affected by three dominance relations: OTM covered-calls dominating over OTM protective-puts, OTM covered-calls dominating over ITM protective-puts, and ITM covered-calls dominating over ITM protective-puts. If all three of these relations hold, then selling covered-calls is optimal; while if none of these relations hold, buying protective-puts is optimal. The weights indicate that the first two dominance relations are twice as important as the third dominance relation in affecting the optimal strategy. Together, these three dominance relations explained $98.3 \%$ of the variation in optimal strategy.

The results of discriminant analysis of the optimal strategy on the characteristics of the distribution of the underlying stock are shown in Table 7.

Table 7. Discriminant analysis of optimal strategy on the characteristics of the distribution of underlying stocks

\begin{tabular}{|l|c|c|}
\hline \multicolumn{3}{|c|}{ Canonical Discriminant Function } \\
\hline & $\begin{array}{l}\text { Standardized } \\
\text { Coefficients }\end{array}$ & $\begin{array}{l}\text { Unstandardized } \\
\text { Coefficients }\end{array}$ \\
\hline mean stock returns & -1.7087 & -315.8150 \\
\hline stdev stock returns & 1.7244 & 131.1379 \\
\hline skewness stock returns & 0.8221 & 0.6990 \\
\hline kurtosis stock returns & 0.0781 & 0.0130 \\
\hline (Constant) & Values at centroids \\
\hline \multicolumn{2}{|c|}{ buy protective-puts } & -3.4535 \\
\hline \multicolumn{2}{|c|}{ sell covered-calls } & -0.2321 \\
\hline
\end{tabular}




\section{Macrothink

The standard deviation of returns and the mean returns of the underlying stock were found to have significant impact on the optimal strategy, followed by the skewness of returns and the kurtosis of returns of the underlying stock. Moreover, the optimal strategy was more likely to involve selling covered-calls for lower standard deviation of returns of the underlying stock and buying protective-puts for higher standard deviation of returns, other characteristics remaining constant; and vice versa for the mean returns of the underlying stock. The discriminant function correctly classified $50.9 \%$ of the sample stocks.

The results of discriminant analysis of selling ITM covered-calls and selling OTM covered-calls on the characteristics of the distribution of the underlying stock are shown in Table 8.

Table 8. Discriminant analysis of selling ITM and OTM covered-calls on

the characteristics of the distribution of underlying stocks

\begin{tabular}{|l|c|c|}
\hline \multicolumn{2}{|c|}{ Canonical Discriminant Function } \\
\hline & $\begin{array}{c}\text { Standardized } \\
\text { Coefficients }\end{array}$ & $\begin{array}{l}\text { Unstandardized } \\
\text { Coefficients }\end{array}$ \\
\hline mean stock returns & 1.0357 & 196.0300 \\
\hline stdev stock returns & -1.9970 & -157.1348 \\
\hline skewness stock returns & 0.2940 & 0.2487 \\
\hline kurtosis stock returns & 0.8668 & 0.1438 \\
\hline (Constant) & 4.0848 \\
\hline \multicolumn{2}{|c|}{ Values at centroids } \\
\hline sell OTM covered-calls & 0.3199 \\
\hline \multicolumn{2}{|c|}{ sell ITM covered-calls } \\
\hline
\end{tabular}

The standard deviation of returns, the mean returns, and the kurtosis of returns of the underlying stock were found to have significant impact on the dominance relation between ITM covered-calls and OTM covered-calls, followed by the skewness of returns of the underlying stock. Moreover, selling OTM covered-calls was more likely to dominate selling ITM covered-calls for lower standard deviation of returns of the underlying stock and vice versa for higher standard deviation of returns, other characteristics remaining constant; and vice versa for the mean returns and the kurtosis of returns of the underlying stock. The discriminant function correctly classified $63.6 \%$ of the sample stocks.

The results of discriminant analysis of buying ITM protective-puts and buying OTM protective-puts on the characteristics of the distribution of the underlying stock are shown in Table 9. 


\section{Ml Macrothink}

Table 9. Discriminant analysis of buying ITM and OTM protective-puts on the characteristics of the distribution of underlying stocks

\begin{tabular}{|l|c|c|}
\hline \multicolumn{3}{|c|}{ Canonical Discriminant Function } \\
\hline & $\begin{array}{l}\text { Standardized } \\
\text { Coefficients }\end{array}$ & $\begin{array}{l}\text { Unstandardized } \\
\text { Coefficients }\end{array}$ \\
\hline mean stock returns & 1.2305 & 230.9568 \\
\hline stdev stock returns & -2.0038 & -153.6011 \\
\hline skewness stock returns & 0.1405 & 0.1195 \\
\hline kurtosis stock returns & 1.3061 & 0.2191 \\
\hline (Constant) & & 3.6477 \\
\hline \multicolumn{2}{|c|}{ Values at centroids } \\
\hline \multicolumn{2}{|c|}{ buy OTM protective-puts } & 0.3540 \\
\hline \multicolumn{2}{|c|}{ buy ITM protective-puts } & -0.2950 \\
\hline
\end{tabular}

The standard deviation of returns, the kurtosis of returns, and the mean returns of the underlying stock were found to have significant impact on the dominance relation between OTM protective-puts and ITM protective-puts, followed by the skewness of returns of the underlying stock. Moreover, buying OTM protective-puts was more likely to dominate buying ITM protective-puts for lower standard deviation of returns of the underlying stock and vice versa for higher standard deviation of returns, other characteristics remaining constant; and vice versa for the kurtosis of returns and mean returns of the underlying stock. The discriminant function correctly classified $58.2 \%$ of the sample stocks.

\section{Discussion}

The results of the study showed that buying protective-puts and selling covered-calls do yield higher returns than a pure-stock position. Overall, buying protective-puts yielded better returns over a pure-stock position than selling covered-calls, but with mixed results, as was observed in earlier studies. The returns from protective-put and covered-call strategies were negatively correlated, and further analysis showed that the mean and standard deviation of the returns distribution of the underlying stock affected the optimal strategy: buying protective-puts was optimal for stocks for which the returns distribution had relatively higher mean values and lower standard deviations, while selling covered-calls was optimal for stocks for which the returns distribution had relatively lower mean values and higher standard deviations. Further, a similar association was found for ITM and OTM options strategies: buying OTM protective-puts was better for stocks for which the returns distribution had relatively higher mean values and lower standard deviations, while buying ITM protective-puts was better for stocks for which the returns distribution had relatively lower mean values and higher standard deviations; similarly, selling OTM covered-calls was better for stocks for which the returns distribution had relatively higher mean values and lower standard deviations, while selling ITM covered-calls was better for stocks for which the returns distribution had relatively lower mean values and higher standard deviations. 
The study suggests that the returns distribution of the underlying stock plays a central role in the optimality of options strategies. The results of present study suggest that the mean returns and the standard deviation of returns affect hedging strategies (i.e. buying protective-puts and selling covered-calls), while the results of Dash et al (2008) suggest that the standard deviation, skewness, and kurtosis of returns affect more aggressive speculative strategies ("hold stock, buy call" and "hold stock, sell put"); in particular, skewness and kurtosis in the daily returns of the underlying stock tend to favour to more aggressive options positions. The results of the present study also suggest that the mean returns and the standard deviation of returns affect ITM and OTM strategies.

The present study has some limitations. The study considers options strategies only for NSE-listed stocks, but the results should be generalisable to other stock exchanges as well, particularly in other emerging economies. Also, the study considers only three-month contracts, for a specific period (viz. $1^{\text {st }}$ October 2007 to $27^{\text {th }}$ December 2007), so that the results obtained may not be generalised to other periods. The results could be due to the overall bull run witnessed by Indian stock markets in the period in question. There is scope for further research to examine the generalisability of the results of the present study; particularly whether the results continue to hold in similar conditions.

A more serious limitation is that the study does not investigate the distributions of daily returns of the option-stock positions, from which even richer results may have been obtained. There is a vast scope for further research to investigate the distributions of daily returns of different option-stock positions and to relate these to the distributions of daily returns of the underlying stocks.

\section{References}

Abid, F., Mroua, M., \& Wong, W.-K. (2009). The Impact of Option Strategies in Financial Portfolios Performance: Mean-Variance and Stochastic Dominance Approaches. Finance India, 23, 503-526.

Benninga, S., \& Blume, M. (1985). On the Optimality of Portfolio Insurance. Journal of Finance, 40(5), 1341-1352. http://dx.doi.org/10.1111/j.1540-6261.1985.tb02386.x

Bookstaber, R., \& Clarke, R. (1985). Problems in Evaluating the Performance of Portfolios with Options. Financial Analysts Journal, 48-62. http://dx.doi.org/10.2469/faj.v41.n1.48

Brooks, R., \& Hand, J. (1988). Evaluating the Performance of Stock Portfolios with Index Futures Contracts. Journal of Futures Markets, 8(1), 33-46. http://dx.doi.org/10.1002/fut.3990080104

Castellano, R., \& Giacometti, R. (2001). Performance of a Hedged Stochastic Portfolio Model in the Presence of Extreme Events. Computational Economics, 17(2/3, 239-252. http://dx.doi.org/10.1023/A:1011632311173

Cox, C. (1976). Futures Trading and Market Information. Journal of Political Economy, 84(6), 1215-1237. http://dx.doi.org/10.1086/260509 


\section{Macrothink}

Asian Journal of Finance \& Accounting ISSN 1946-052X

Dash, M, Kavitha V., Deepa, K.M., \& Sindhu, S. (2008). A Study of Optimal Stock and Options Strategies. SSRN Working Paper Series, Abstract No. 1293203.

Dash, M., Narendra Babu, N., \& Kodagi, M. (2007). Speculation Strategies Using Investment in Options. Indian Journal of Finance, 1(4), 3-8.

Dybvig, P., \& Ingersoll, J. (1982). Mean-Variance Theory in Complete Markets. Journal of Business, 55(2). 233-251. http://dx.doi.org/10.1086/296162

Hakansson, N. (1978). Welfare Aspects of Options and Supershares. Journal of Finance, 33, 759-776. http://dx.doi.org/10.2307/2326472

Isakov, D., \& Morard, B. (2001). Improving Portfolio Performance with Option Strategies: Evidence from Switzerland. European Financial Management, 7(1), 73-91. http://dx.doi.org/10.1111/1468-036X.00145

Ross, S. (1976). Options and Efficiency. Quarterly Journal of Economics, 90(1), 75-89. http://dx.doi.org/10.2307/1886087

Trennepohl, G., \& Dukes, W. (1981). An Empirical Test of Option Writing and Buying Strategies utilizing In-the-money and Out-of-the-money Contracts. Journal of Business Finance \& Accounting, 8(2), 185-202. http://dx.doi.org/10.1111/j.1468-5957.1981.tb00813.x 